\section{Commentary: The need for better identification of postoperative delirium}

\author{
Subhasis Chatterjee, $\mathrm{MD},{ }^{\mathrm{a}, \mathrm{b}}$ and \\ Daniel T. Engelman, MD ${ }^{\mathrm{c}}$
}

"When sleep puts an end to delirium, it is a good symptom."

$$
\text { - Hippocrates }{ }^{1}
$$

Among adverse events, delirium does not typically capture a surgeon's attention to the same degree as stroke, acute renal failure, or reoperation. However, compelling data suggest that post-cardiac surgery delirium has an almost $20 \%$ incidence, is a source of major morbidity, and decreases survival. $^{2}$ Dubiel and colleagues ${ }^{3}$ provide valuable insight into the vexing problem of delirium and whether the Society of Thoracic Surgeons (STS) Adult Cardiac Surgery Database adequately captures its true incidence. The central concern is that the current STS definition is too restrictive, mostly identifying cases with hyperactive symptoms (eg, agitation) and often missing the more insidious, hypoactive symptoms of delirium that occur in approximately $50 \%$ of cases. Instead, the authors suggest that clinicians use a systematic screening tool, such as the Confusion Assessment Method in the Intensive Care Unit (CAM-ICU) or the Intensive Care Delirium Screening Checklist, which is designed to capture the full spectrum of delirium presentation. The authors should be congratulated for their numerous contributions to and leadership in enlightening the cardiac surgery community about the significance of postoperative delirium.

\footnotetext{
From the ${ }^{a}$ Divisions of General and Cardiothoracic Surgery, Michael E. DeBakey Department of Surgery, Baylor College Medicine, Houston, Tex; ${ }^{\mathrm{b}}$ Department of Cardiovascular Surgery, Texas Heart Institute, Houston, Tex; and ${ }^{c}$ Heart and Vascular Program, Baystate Health, University of Massachusetts Medical School-Baystate, Springfield, Mass.

Disclosures: The authors reported no conflicts of interest.

The Journal policy requires editors and reviewers to disclose conflicts of interest and to decline handling or reviewing manuscripts for which they may have a conflict of interest. The editors and reviewers of this article have no conflicts of interest.

Received for publication July 7, 2020; revisions received July 7, 2020; accepted for publication July 10, 2020; available ahead of print July 15, 2020.

Address for reprints: Daniel T. Engelman, MD, Heart and Vascular Program, Baystate Health, 759 Chestnut St, Springfield, MA 01199 (E-mail: daniel.engelman@ baystatehealth.org).

J Thorac Cardiovasc Surg 2022;163:735-6

$0022-5223 / \$ 36.00$

Copyright (c) 2020 by The American Association for Thoracic Surgery

https://doi.org/10.1016/j.jtcvs.2020.07.039
}

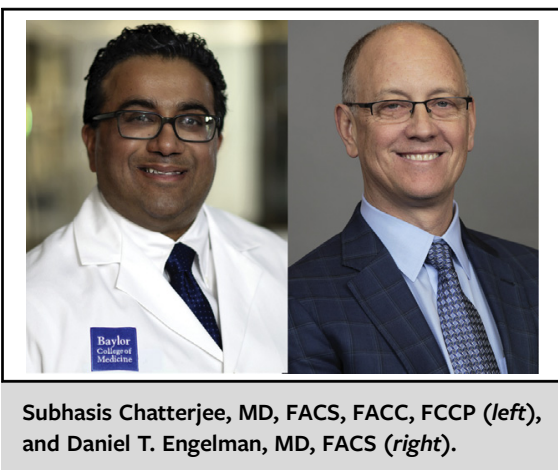

CENTRAL MESSAGE

Accurate identification of delirium allows recognition, prevention, and treatment.

Although critical care practitioners should be readily familiar with the CAM-ICU score, given its wellestablished role in diagnosing delirium in mechanically ventilated patients, ${ }^{4}$ for the sake of clarification, delirium is defined as follows: an acute change or fluctuation in mental status, inattention, and either an altered level of consciousness or disorganized thinking. The well-validated CAM-ICU method showed a sensitivity of $80 \%$ and specificity of $96 \%$ for detecting delirium.

Dubiel and associates ${ }^{3}$ retrospectively reviewed a database of almost 5000 patients treated over a nearly 6-year period, with a primary end point of 1-year functional survival. Patients were stratified to an earlier era in which the STS definition was used to identify delirium $(n=2756)$, or a later era during which the CAM-ICU method was used $(\mathrm{n}=2236)$. Propensity-score matching produced 1835 matched pairs. Approximately $10 \%$ of patients were octogenarians, 9\% were considered high-risk by Acute Physiology and Chronic Health Evaluation II score, and $63 \%$ underwent isolated coronary artery bypass grafting. The authors found a much higher incidence of delirium with the CAM-ICU method than with the STS method $(13 \%$ vs $8 \%)$; this difference was even more pronounced in the octogenarian cohort $(28 \%$ vs $16 \%)$. In addition, the CAM-ICU scoring method independently predicted adverse outcomes (hazard ratio, 2.58), whereas the current STS definition did not. Lastly, rehospitalizations were substantially more frequent during the CAM-ICU era.

A core challenge is that few therapeutic interventions are available for delirium. Pieri and colleagues, ${ }^{6}$ in a large systematic review of 56 randomized trials in cardiac surgery focusing on delirium, found that 51 of the studies focused 
on prevention, whereas only 5 focused on treatment. From their exhaustive literature review, the authors' sole recommendation was that dexmedetomidine "might reduce the occurrence of delirium after cardiac surgery." Recent trials of prophylactic haloperidol and ziprasidone have demonstrated no benefit with either drug over placebo in preventing delirium. ${ }^{7,8}$ Nonetheless, recent surveys indicate that $60 \%$ to $85 \%$ of clinicians continue to routinely treat most cases of delirium with medications (eg, benzodiazepines or antipsychotics). ${ }^{9,10}$ The authors correctly point out that there has not yet been a randomized controlled trial of screening methods that could help determine whether earlier identification makes a difference in outcomes.

Thus, although replacing the STS's current delirium screening method with the CAM-ICU appears desirable, we must be circumspect about what we can hope to achieve. Although the CAM-ICU score captures hypoactive delirium - the type of delirium seen in up to $85 \%$ of postcardiac surgery cases ${ }^{11}$ - there are no magic bullets here. It would be useful to determine whether the frequency of positive CAM-ICU results is associated with differential outcomes. In other words, rather than an all-or-nothing approach, it would appear that having 1 positive CAMICU result is different from having multiple positive CAM-ICU results over consecutive nursing shifts. Confirming this difference could tell us whether earlier diagnosis makes a difference.

Delirium prevention, recognition, and management do not come naturally to many cardiac surgeons. After all, training in cardiac surgery emphasizes rapid recognition of a clinical problem and decisive action, either surgical or medical, to attempt to resolve it. The clinical problem of delirium is optimally managed under the comprehensive ABCDEF bundle of care, ${ }^{2,10}$ which has the following components: ${ }^{10}$

- Assess, prevent, and manage pain;

- Both spontaneous awakening trials and spontaneous breathing trials;

- Choice of analgesia and sedation;

- Delirium: assess, prevent, and manage;

- Early mobility and exercise; and

- Family engagement and empowerment.

However, the surgeon's role in delirium management is to remind the interdisciplinary team to look for signs of delirium each day and aim to prevent it. The use of tools such as the CAM-ICU screening each nursing shift is critical to this process. ${ }^{12}$ However, nothing focuses a care team's attention on a given concern as much as knowing that the surgeon is vested in its occurrence, whether it is mobility, early extubation, minimizing transfusions, or any of a host of other quality measures. Strategies to reduce the incidence of delirium should include early mobility, judicious use of opioid analgesics, avoiding certain sedative medications (eg, benzodiazepines) where possible, and promoting sleep hygiene.

Indeed, in time, the goal should be to make CAM-ICU assessment a routine part of patient evaluation on interdisciplinary ICU rounds, similar to the hemoglobin or serum creatinine level. The CAM-ICU score provides an ICU quality metric for the incidence of delirium. The most recent version of the STS database (4.20; effective July 2020) captures additional components of delirium (eg, lethargy-stupor, although not the formal CAM-ICU) but still falls short of encompassing the full spectrum of delirium, specifically the hypoactive variant. ${ }^{13}$

Dubiel and colleagues ${ }^{3}$ have made a valuable contribution to defining the scope of the delirium problem. Hippocrates would probably agree that evaluating the efficacy of preventive strategies is the logical next step.

\section{References}

1. The Aphorisms of Hippocrates, 460 B.C. Available at: https://quotecatalog.com/ quote/Ya8bWn7/. Accessed July 22, 2020.

2. Arora RC, Djaiani G, Rudolph JL. Detection, prevention, and management of delirium in the critically ill cardiac patient and patients who undergo cardiac procedures. Can J Cardiol. 2017;33:80-7.

3. Dubiel C, Hiebert BM, Stammers AN, Sanjanwala RM, Tangri N, Singal RK, et al. Delirium definition influences prediction of functional survival in patients one-year postcardiac surgery. J Thorac Cardiovasc Surg. 2022;163:725-34.

4. Ely EW, Inouye SK, Bernard GR, Gordon S, Francis J, May L, et al. Delirium in mechanically ventilated patients: validity and reliability of the confusion assessment method for the intensive care unit (CAM-ICU). JAMA. 2001;286:2703-10.

5. Gusmao-Flores D, Salluh JI, Chalhub RA, Quarantini LC. The confusion assessment method for the intensive care unit (CAM-ICU) and intensive care delirium screening checklist (ICDSC) for the diagnosis of delirium: a systematic review and meta-analysis of clinical studies. Crit Care. 2012;16:R115.

6. Pieri M, De Simone A, Rose S, De Domenico P, Lembo R, Denaro G, et al. Trials focusing on prevention and treatment of delirium after cardiac surgery: a systematic review of randomized evidence. J Cardiothorac Vasc Anesth. 2020;34: 1641-54.

7. Girard TD, Exline MC, Carson SS, Hough CL, Rock P, Gong MN, et al. Haloperidol and ziprasidone for treatment of delirium in critical illness. $N$ Engl J Med. 2018;379:2506-16.

8. van den Boogaard M, Slooter AJC, Bruggemann RJM, Schoonhoven L, Beishuizen A, Vermeijden JW, et al. Effect of haloperidol on survival among critically ill adults with a high risk of delirium: the REDUCE randomized clinical trial. JAMA. 2018;319:680-90.

9. Devlin JW, Bhat S, Roberts RJ, Skrobik Y. Current perceptions and practices surrounding the recognition and treatment of delirium in the intensive care unit: a survey of 250 critical care pharmacists from eight states. Ann Pharmacother. 2011;45:1217-29.

10. Morandi A, Piva S, Ely EW, Myatra SN, Salluh JIF, Amare D, et al. Worldwide survey of the "assessing pain, both spontaneous awakening and breathing trials, choice of drugs, delirium monitoring/management, early exercise/mobility, and family empowerment" (ABCDEF) bundle. Crit Care Med. 2017;45:e1111-22.

11. Klugkist M, Sedemund-Adib B, Schmidtke C, Schmucker P, Sievers HH, Huppe M. Confusion assessment method for the intensive care unit (CAMICU): diagnosis of postoperative delirium in cardiac surgery. Anaesthesist. 2008;57:464-74 [Article in German].

12. Engelman DT, Ben Ali W, Williams JB, Perrault LP, Reddy VS, Arora RC, et al. Guidelines for perioperative care in cardiac surgery: enhanced recovery after surgery society recommendations. JAMA Surg. 2019;154:755-66.

13. Society of Thoracic Surgeons SCA data specifications v4.20.2. Available at: https://www.sts.org/sites/default/files/Training\%20Manual\%20V4_20_2\%20 July\%202020.pdf. Accessed July 2, 2020. 